\title{
Vivências de Prazer e Sofrimento no Trabalho em Professores de KaRATE 1
}

\author{
Experiences of pleasure and suffering at work in karate teachers
}

CAMILO, Juliana ${ }^{2}$ RUBIO, Katia ${ }^{3}$

\begin{abstract}
RESUMo
Este estudo investiga as vivências de prazer e sofrimento com o trabalho de professores de Karate em uma cidade metropolitana do estado de São Paulo. Para isso, como aporte epistemológico, empregamos a psicodinâmica do trabalho. Foram feitas sete entrevistas individuais com os professores, no ano de 2019. Os resultados indicaram a invisibilidade do trabalho desses educadores, laços extremamente frágeis contratuais, condições precárias estruturais para que as aulas fossem ministradas, alta demanda dos alunos quanto as competências dos professores e alta expectativa dos alunos e seus cuidadores quanto aos princípios disseminados nas aulas. Ressalta-se as estratégias defensivas que, por respeito a hierarquia e disciplina do Karate, além do receio de perder os postos de trabalho (equivalente ao desemprego), submetem-se as organizações com o mínimo de questionamento, aceitando condições precárias laborais. As vivências de prazer são maximizadas, ao se atuar com alunos de projetos sociais, assim como pela possibilidade de auxiliá-los com outros referenciais para além dos problemas sociais por eles vivenciados.
\end{abstract}

Palavras-chave: Psicodinâmica do trabalho. Psicologia do Esporte. Artes Marciais.

\section{ABstract}

This study investigates the experiences of pleasure and suffering with the work of karate teachers in a metropolitan city of the state of São Paulo. The work psychodynamics was used as a theoretical approach. Seven individual interviews were conducted with the teachers in 2019. The results indicate the invisibility of the work, extremely fragile contractual ties, poor structural conditions for the classes to be taught, high student demand for teachers' skills and high expectations of the teachers. students and their caregivers about the principles disseminated in class. It is important to stress the defensive strategies that, out of respect for the hierarchy and discipline of karate, in addition to the fear of losing the jobs (unemployment), organizations are submitted with the least questioning. The experiences of pleasure are maximized by working with students of social projects, as well as by the possibility of assisting them with other referential besides the social problems they face.

Keywords: Work psychodynamics. Sport Psychology. Martial Arts.

\section{INTRODUÇÃO}

\footnotetext{
1 Texto não publicado em encontros e/ou eventos científicos. Aprovado pelo Comitê de Ética em Pesquisa da Universidade de São Paulo. Obteve financiamento parcial pelo PIPEQ/PUCSP. Resultante de pesquisa de pós-doutoramento da primeira autora, intitulada de "As modalidades esportivas de combate em uma cidade metropolitana do estado de São Paulo".

${ }^{2}$ Pós-doutorado em Educação Física e do Esporte pela Universidade de São Paulo. Doutorado e Mestrado em Psicologia Social pela PUCSP. Psicóloga e Professora da Pontifícia Universidade Católica de São Paulo, no curso de Psicologia e da Universidade Paulista (desde 2007). E-mail: julianacamilo8@gmail.com

${ }^{3}$ Pós-doutorado em Psicologia Social pela Universidad Autonoma de Barcelona. Doutorado em Educação pela USP. Mestrado em Educação Física e do Esporte pela USP. Psicóloga e Jomalista. Professora associada da Faculdade de Educação da Universidade de São Paulo. E-mail: katrubio@usp.br
} 
O objetivo desta pesquisa foi investigar as vivências de prazer e sofrimento com o trabalho em professores de Karate, na cidade de Cotia, região metropolitana do estado de São Paulo. A cidade de Cotia, área remanescente do cinturão verde paulistano e local protegido pela Lei dos Mananciais, apresenta realidades díspares em âmbito socioeconômico e demográfico (DRENATEC ENGENHARIA S/C; INSTITUTO DE PESQUISAS TECNOLÓGICAS, 2007). De um lado tem-se a urbanidade de condomínios fechados e luxuosos na região da Granja Vianna, de outros territórios com moradias precárias, permeado por desigualdades sociais e violências, como os bairros Parque Manuel Mirizola e Lajeado. Ao redor há ainda condomínios menores e horizontais, com casas voltadas para o público de padrão médio, como os bairros Bosque Capuava e Jardim Belizário. A cidade conta com polos industriais, comércios de pequeno e médio porte e área agrícola, administrada sobretudo pela comunidade japonesa.

Ainda que as lutas tenham importância histórica em solo brasileiro, sendo parte da cultura do país e, como tantas outras modalidades esportivas, fundamentais para fomentar a Educação, a Saúde, o Desenvolvimento e a Paz (ORGANIZAÇÃO DAS NAÇÕES UNIDAS NO BRASIL, 2016), seus educadores ou formadores, que em tese são fundamentais nesse processo, parecem não receber o mesmo olhar, sobretudo, quando se trata do reconhecimento do seu papel enquanto trabalhador. Neste contexto de trabalho os professores são predominantemente atuantes em uma atividade não regulada (sem um registro na carteira profissional ou minimamente um contrato formal), que acabam por ficar à mercê de uma lógica hiperflexibilizada, na qual pouco se chegou os direitos e conquistas históricas de outras tantas categorias profissionais (CAMILO; SPINK, 2018; CAMILO, 2020).

Estamos aqui em um reduto marcado por relações de trabalho que se apoiam na obediência e submissão, sublinhada ainda por padrões desiguais entre regiões e trabalhadores, facilitada pela ausência de alguma organização reivindicatória de direitos e melhores condições laborais. Tal como já postulava (ANTUNES, 2011) Antunes (2008, 2011), ao analisar a área de serviços, temos aqui igualmente, inúmeras pressões competitivas, uma rede de subcontratação e deslocamentos, de modo a dispor de força de trabalho que se adapta ao mercado consumidor. As consequências mais evidentes, nas palavras de Antunes, é a heterogeneização, a fragmentação e complexificação desta classe trabalhadora. Convergente a esta discussão Druck (2016), ao falar da terceirização que assola inúmeras áreas como a de serviços, aponta o uso predatório da força de trabalho dessas classes trabalhadoras na sua forma mais aguda. Para a autora tem-se aqui o desrespeito dos limites físicos dos trabalhadores, expondo-os a riscos de morte com as formas de trabalho que transgridem a condição humana.

Partindo da premissa que a Psicologia do Trabalho tem muito a oferecer em termos de análise e proposições, se faz fundamental também que este campo do conhecimento se aproprie desta e outras tantas realidades que envolvem o contexto esportivo, tal como apontado em estudos anteriores. Ao se apropriar e se aprofundar neste mercado laboral e de intenso consumo, a Psicologia do Trabalho poderá notar que se tem aqui modos de produção que extrapolam (e muito) os contextos tradicionais (fábricas, áreas de prestação de serviços, varejo, etc.), mas que, igualmente, criam ganhos, a partir da 
exploração da mão-de-obra, gerando oportunidades de trabalho e vivências de prazer, ao lado de sofrimentos, acidentes e adoecimentos diversos.

Assim sendo, a concepção adotada neste estudo parte do pressuposto que os professores aqui analisados são trabalhadores. São pessoas que, como os diferentes indivíduos assalariados inseridos em uma lógica tradicional, vendem o seu tempo, a sua habilidade, emprestam os seus corpos, nomes e subjetividades para um determinado fim, tal como os atletas de rendimento (CAMILO; RABELO, 2019; FERREIRA JUNIOR; RABELO; CAMILO, 2019).

No entanto, a atividade laboral dos professores de lutas, quando comparada a outros campos de atuação pedagógica, ainda é pouco visibilizada e problematizada, especialmente quando se consideram, como no caso das lutas, as diferentes formações de acesso ao patamar de instrutor ou professor. É importante contextualizar que há uma questão importante no cenário brasileiro, que foi bastante explorada em âmbito jurídico e debatida na coletividade das lutas, sobre a necessidade (ou não) dos professores serem profissionais de Educação Física (com formação superior, licenciatura e/ou bacharelado em Educação Física). Esta controvérsia parece minimamente ter sido reduzida após o Supremo Tribunal de Justiça (STJ), no julgamento do Recurso Especial 1012692/RS (2011), ter decidido que:

Quanto aos artigos $1^{\circ}$ e $3^{\circ}$ da Lei n. 9.696/1998, não se verificam as alegadas violações, porquanto não há neles comando normativo que obrigue a inscrição dos professores e mestres de danças, ioga e artes marciais (Karate, judô, tae-kwon-do, kickboxing, jiu-jitsu capoeira etc.) nos Conselhos de Educação Física, porquanto, à luz do que dispõe o art. $3^{\circ}$ da Lei n. 9.696/1998, essas atividades não são caracterizadas como próprias dos profissionais de educação física (Supremo Tribunal de Justiça, 2011).

A partir desta decisão, os Conselhos de Educação Física ficaram impedidos de fiscalizar os instrutores de lutas, danças e ioga sob pena do cometimento do ilícito de abuso de autoridade, previsto no art. $6^{\circ}$ da Lei 4.898/65.

É neste contexto que se insere os professores que serão aqui apresentados, envolvidos com a periferia, com o gueto, com a negritude, com o aprendizado da defesa e do ataque, que são muitas vezes fundamentais para a sobrevivência desde a infância em situações sociais críticas (WACQUANT, 2003; SPENCER, 2014). Igualmente, atuam nas classes mais abastadas, em que se destaca a modalidade como bem-estar, saúde, esporte e toda a sua lógica competitiva, a tradição familiar ou cultural ou, ainda, como forma de defesa pessoal, como pode ser o caso do jiu-jitsu (AWI, 2012), da esgrima ou kendo. Em suma, se as lutas corporais podem ser um modo potente para o fomento da educação, de contenção da agressão, da socialização, sobretudo nos bairros pobres em que o acesso aos aparatos de lazer é escasso ou inexistente, também podem ser usados como bem-estar, para a qualidade de vida ou para a defesa pessoal, como se nota empiricamente nos bairros mais abastados.

As artes marciais orientais são um elemento constitutivo da cultura corporal do país, sendo a cidade de São Paulo um importante polo de fomento à atividade. Permeadas por valores humanísticos, as artes marciais foram sendo desenvolvidas como uma forma de sobrevivência e, mais tarde, repensadas enquanto práticas para desenvolvimento pessoal e esportivo no mundo moderno (BARREIRA, 2014)

Nessa direção encontra-se o Karate-Dō, que é uma disciplina de desenvolvimento pessoal com práticas de luta que foi originada em Okinawa (antigamente a principal ilha 
do arquipélago de Ryukyu) entre a China e o Japão. Okinawa era um reino independente e vassalo da China no século XIV, sendo bem documentado apenas a partir de 1867, embora haja registros anteriores de sua existência, mas insuficientes para um detalhamento consistente de sua história prévia, período em que surgia o Karate- Dō (OLIVEIRA; TELLES; BARREIRA, 2019). Na sua origem, essa disciplina chamava-se Te (手), mão, ou mão de Okinawa, vindo a denominar-se Tōde (唐手), em Uchināguchi (o idioma de Okinawa) ou Karate (唐手), pronúncia japonesa para a mesma escrita, após os contatos com as artes marciais chinesas, em especial o Quan Fa (FUNAKOSHI, 1973).

Desenvolvido sob a influência de diversas culturas, em especial da japonesa e chinesa, o Karate-Dō se tornou uma disciplina híbrida, multicultural e pluritemática (Camps \& Cerezo, 2005). Seu conjunto de valores também representa essa pluralidade, pois se alicerçou a partir dos ideais de inúmeros mestres antigos e modernos (BARREIRA, 2014).

A modalidade é permeada por princípios filosóficos que são entendidos como fundamentais para "polir" o caráter. Nesse sentido, o praticante deve manter a mente distante do egoísmo e da maldade, devendo buscar a pureza de pensamentos, reagindo apenas quando em ameaça (BARREIRA, 2014). Tem-se aqui o significado filosófico do sufixo "Kara" (vazio) e Tê (Mão), da palavra Karate, que significa a ausência de pensamentos destrutivos ou inferiores, significando também, a Arte de Lutar com as mãos vazias.

Os princípios do Karate são normalmente recitados no começo e no fim das aulas no dojo (local de treinamento). O objetivo é reforçar para os praticantes a ideia de que a arte marcial é antes de tudo um instrumento de aperfeiçoamento pessoal, um modelo de perseverança e temperança, que se deve levar para a vida cotidiana. A seguir será apresentado no Quadro 1 os princípios do Karate na língua japonesa, seguido de sua tradução livre:

Quadro 1- Princípios do Karate

\begin{tabular}{|l|}
\hline \\
\hline Hitotsu: jinkaku kansei ni tsutomuru koto \\
\hline (Primeiro: Esforço para formação do caráter) \\
\hline Hitotsu: makoto no michi wo mamoru koto \\
\hline (Primeiro: Fidelidade para com o verdadeiro caminho da razão) \\
\hline Hitotsu: doryōku no seishin wo yashinau koto \\
\hline (Primeiro: Cultivar um espírito de esforço) \\
\hline Hitotsu: reigi wo omonzuru koto \\
\hline (Primeiro: Respeito acima de tudo) \\
\hline Hitotsu: kekki no yū wo imashimuru koto \\
\hline (Primeiro: Conter o espírito de agressão) \\
\hline
\end{tabular}

Embora os princípios estejam organizados em uma determinada ordem, nenhum é mais importante que o outro. Essa comum importância fica evidente quando lemos Hitotsu 
(Primeiro) no início das frases, incluído para que os praticantes não entendessem algum item do como mais importante do que o outro.

É importante ainda destacar a proximidade atual do Karate com a lógica da esportivização trazida pelo olimpismo - tal como proposto por Pierre de Coubertin (18631937) - tendo em vista sua inclusão nos Jogos Olímpicos de Tóquio 2020. Para Oliveira et al. (2018), percebe-se que a espotivização do Karate tem gerado sua descaracterização e afastamento dos objetivos e princípios originais, passando de uma modalidade de "mãos vazias" para "mãos com luvas", em alusão a profissionalização e adaptação da modalidade para a inclusão nos grandes eventos esportivos.

\section{ASPECTOS CONCEITUAIS}

Para discutir a complexa trama envolvida em torno destes trabalhadores, daremos foco nas suas vivências de prazer e sofrimento, a partir do caminho epistemológico feito pela psicodinâmica do trabalho (PDT), sobretudo vinculada a escola dejouriana de pensamento (DEJOURS, 2004, 2011; DEJOURS; NETO, 2012; DEJOURS; BARROS; LANCMAN, 2016). A psicodinâmica do trabalho desenvolveu-se a partir dos estudos em psicopatologia do trabalho, entre os anos de 1950-1960, tendo como principais exponentes: L. Le Guilant, C. Veil, P. Sivadon, A. Fernanadez-Zoïla e J. Bégoinda (DEJOURS, 2011).

Um dos principais avanços propiciados por esta corrente de pensamento, foi o reconhecimento da normalidade e do prazer envolvido no contexto do trabalho abrindo caminhos para além da equação ofício-sofrimento. Neste sentido, a PDT busca compreender como os trabalhadores podem manter um certo equilíbrio psíquico, mesmo estando submetidos a condições de trabalho desestruturantes (DEJOURS, 2004). Além disso, a PDT evidenciou o sofrimento psíquico desde o estado pré-patológico, permitindo que se possa atuar na identificação das consequências das organizações do trabalho sobre a saúde mental dos trabalhadores, assim como na possibilidade de se pensar em intervenções preventivas e transformadoras (MOLINIER, 2016). É importante ressaltar, que nessa concepção, o sofrimento é o modo de evitar a patologia, já que o trabalhador ao mesmo tempo que se angustia, busca o equilíbrio e modos de fazer (em seus aspectos individuais e coletivos), fazendo frente as experiências de fracasso e tensão decorrentes do contato com o trabalho real (MERLO; MENDES, 2009).

A abordagem adotada por essa disciplina permitiu também ultrapassar uma visão reducionista e individualizante, que atribuída ao trabalhador única e exclusivamente os impactos do trabalho sobre sua saúde. Nesse sentido, a saúde mental para a psicodinâmica coloca-se entre a patologia e a normalidade, ou seja, resulta dos modos como os sujeitos-trabalhadores reagem e agem frente ao sofrimento originado nos constrangimentos impostos pela organização do trabalho (DEJOURS; BARROS; LANCMAN, 2016).

Assim, falar em custo humano no trabalho, de sofrimento ou prazer, requer a compreensão dos fatores objetivos e subjetivos envolvidos, capazes de afetar os professores aqui estudados.

\section{MÉTOdO}


A discussão que será aqui apresentada parte de retratos obtidos por meio de entrevistas abertas com os professores de Karate, localizados na cidade de Cotia/SP, em 2019.

De acordo com Merlo e Mendes (2009), predomina no Brasil os estudos em PDT que primam pelo uso da abordagem para a leitura teórica do fenômeno estudado, como é o caso desta pesquisa, não adotando os aspectos metodológicos defendido por Dejours. Ainda assim, para os autores, as diferentes perspectivas metodológicas assumidas pelos estudos em psicodinâmica do trabalho, acabam por oferecer contribuições valiosas para o crescimento do campo, refletindo as possibilidades da construção do conhecimento em determinados locais e realidades.

\section{PARTICIPANTES}

As pessoas entrevistadas foram indicadas pelo principal professor de Karate da cidade (sensel), em atendimento ao perfil solicitado pela primeira pesquisadora deste artigo: ter mais de 18 anos e mais de 3 anos de experiência como professor de luta. Cabe dizer que este professor foi um dos precursores da modalidade na cidade, tendo se formado com o mestre japonês encarregado pela disseminação desse estilo de Karate no país, sendo ainda o responsável pela formação da maior parte dos professores da cidade.

Assim, dentro dos critérios estabelecidos, foram indicados para entrevista 7 professores, sendo 6 homens e 1 mulher, correspondendo a amostra total daqueles indicados pelo sensei. Em relação à formação das pessoas entrevistadas, 4 eram profissionais de educação física, 1 administrador de empresas e 2 não possuíam formação superior. Sete deles relataram ter mais de 10 de experiência como professor(a) de Karate em várias realidades (academias de ginástica, academia de lutas, escolas e projetos sociais) e 1 deles 4 anos de experiência em academia de ginástica. A idade dos professores variou entre 30 e 56 anos. Todos eles já foram professores de diferentes públicos: crianças, adolescentes, adultos e idosos.

\section{INSTRUMENTOS}

Este estudo se insere em uma pesquisa de pós-doutorado da primeira autora deste artigo que buscou compreender as modalidades esportivas de combate em uma cidade metropolitana na cidade de São Paulo, assim como o seu trânsito e seus sentidos, que se iniciou em 2018 e teve seu término em 2020. Em um momento inicial foram realizadas entrevistas semi-dirigidas com professores de lutas, vinculados a projetos sociais, escolas, academias de ginástica, academias específicas de lutas e aulas particulares.

A pergunta desencadeadora era "conte-me sua história de vida e como o Karate se inseriu nela", compreendendo que, ao narrar a sua história, a pessoa seleciona eventos e experiências que lhe são afetivamente significativas e que dão ao discurso contornos particulares. A partir da narrativa das pessoas entrevistadas foram feitas intervenções com o objetivo de clarificar alguma dúvida, tomando o cuidado de não trazer uma nova problemática e desviar do aspecto amplo da fala. Em linhas gerais, cada entrevista teve em média 40 minutos de duração, tendo sido gravada, transcrita e validada (confirmadas pelos participantes, com partes incluídas pelos entrevistados a posteriori).

\section{Procedimento de coleta de dados e cuidados Éticos}


As entrevistas foram feitas presencialmente, na academia em que a pessoa entrevistada se vinculava, e em um local reservado, de modo a garantir a privacidade. Estas foram agendadas previamente respeitando a disponibilidade de horário dos participantes.

Esta pesquisa foi aprovada pelo Comitê de Ética em Pesquisa com Seres Humanos da Universidade de São Paulo (USP), tendo seguido os procedimentos metodológicos aqui narrados, garantindo o cumprimento integral da Resolução 510/16 do Conselho Nacional de Saúde. Sendo assim, todos os participantes foram esclarecidos e assinaram um Termo de Consentimento Livre e Esclarecido antes da participação no estudo. Para garantir o sigilo na identificação dos sujeitos, apresentaremos o nome apenas a partir da letra inicial dele.

\section{Procedimento de AnÁlise}

As entrevistas foram lidas em profundidade pelas pesquisadoras responsáveis para a posterior localização de categorias em comum, seguindo a proposta de Mendes (2007) de construção de Análise dos Núcleos de Sentido (ANS). Assim, os dados foram coletados e categorizados por meio da identificação dos temas abordados nas narrativas e identificados pelas pesquisadoras. Esses núcleos formaram categorias que orientaram a análise dos dados conforme a proposta teórica da Psicodinâmica do Trabalho: a saber: condições de trabalho, sobre o sofrimento no trabalho e sobre o prazer no trabalho.

Chamou-nos a atenção que, ao narrar a história de vida e a presença da arte marcial nela, todos os entrevistados trouxeram espontaneamente questões que se vinculavam ao trabalho, suas vivências de prazer e de angústia com o seu ofício. Por este motivo, recortamos das falas todos os trechos que discorriam sobre as vivências profissionais e o modo como elas eram experienciadas. Após leitura densa delas chegou-se a três categorias principais: condições de trabalho, vivências de prazer e de sofrimento com no trabalho.

\section{Resultados}

\section{SOBRE AS CONDIÇÕES DE TRABALHO}

Para efeito de delimitação, entendemos aqui por condições de trabalho, as diferentes consequências que um trabalhador pode sofrer em função da execução de seu ofício, podendo ser em decorrência do aparato físico disponível, da organização e dimensionamento do trabalho ou ainda da relação contratual estabelecida (salário, benefícios, bônus).

Neste sentido, é importante retomar que todas as pessoas entrevistadas relataram experiência no ensino do Karate em diferentes bairros da cidade, tanto aqueles considerados classe alta ou média alta, quanto os de classe média ou que vivem em situação de extrema pobreza. Há, no entanto, um fio condutor quando se pensa em condições de trabalho à luz das diferentes realidades. Ainda que a condição socioeconômica seja extremamente desigual entre os bairros, este é minimamente convertido em melhores condições de trabalho aos professores: "Para o aluno eles se apresentam de uma maneira, que é melhor academia, o melhor espaço, mas internamente conversando é só a redução de custo. Chegaram até na última academia que eu trabalhei, na reunião, chega lá e falar da água que os alunos bebiam. A água é 
essencial, o cara está pagando mensalidade. E eu vou defender o meu aluno". (Professor R. 47 anos. 12 anos como professor de Karate. Fevereiro de 2019).

Ao relatar o que ocorre em academias localizadas em bairros de classe média 0 professor R. aponta o descompasso entre o que é apresentado ao aluno e o que de fato ocorre nos bastidores destes espaços. $\mathrm{O}$ controle exercido pelos proprietários sobre 0 seu trabalho, as reuniões de alinhamento para contenção de gastos que chegam ao limite do suportável, versando até sobre o improvável: o racionamento da água bebida pelos alunos. Neste sentido a fala de $\mathrm{H}$. é igualmente impactante, quando se analisa a discrepância entre as condições de trabalho, ao analisar bairros com alto poder aquisitivo e outros que vivem em pobreza ou extrema pobreza: "A diferença quando você chega num bairro que tem um poder aquisitivo alto, que hoje em Cotia nós podemos falar da Granja Viana, é que quando você chega lá, e a pessoa olha para sua cara te esnobando. A partir do momento que você entra como várias vezes eu fui dar aula: 'Você veio a pé? Você não tem carro? Como você não tem carro?' ou ele chega lá: 'ah, me dá aula particular, eu te dou um carro, não tem problema, é para você vir'. Ele mostra que tem condição de comprar você inúmeras vezes. Mas ele não entende que você compra o Curriculum, não o caráter". (Professor H. 30 anos. 16 anos como professor de Karate. Fevereiro de 2019)

Como tolerar o intolerável? Para Dejours (2006) um trabalhador invisibilizado não suscita a indignação, cólera ou ação coletiva. Isso só poderá ocorrer quando "se estabelece uma associação entre a percepção de sofrimento alheio e a convicção que este sofrimento resulta em uma injustiça (DEJOURS, 2006, p. 19)". Concordando com o autor entendemos que nem todos partilham do mesmo ponto de vista, segundo o qual as vítimas da pobreza, exclusão social, desemprego, são também vítimas de uma injustiça social ampla. Para aqueles que naturalizam o mal, na fala do professor $\mathrm{H}$. os moradores dos bairros da Granja Viana e Alphaville (que fica em outra cidade), o sofrimento é uma adversidade e, obviamente, não reclamação reação política. Vê-se aqui também que, tal como discorre Dejours (2006), por condições de trabalho, há não somente o espaço físico e os contratos de trabalho, mas as relações subjetivas implicadas neste processo.

As estruturas físicas também colocam em xeque a segurança dos(as) alunos(as) e exercem significativa pressão nos professores: "Teve 6 anos que eu dei aula como voluntaria em escola municipal, só que dava aula em local externo. O chão era de barro, de terra e de pedra. Então você não podia ficar descalço, porque se machucava. Era mais de 100 alunos, uma turma enorme. E eu dava aula lá, sempre com a promessa de que ia abrir uma sala e um tatame, e aí passou 1 ano, passaram 2, 3, eu fui conseguindo graduar a turma, só que chega uma época que para graduar você precisa saber cair, por exemplo, e a falta de tatame inviabilizava. As condições de lá não eram favoráveis". (Professora E. 44 anos. 15 anos como professora de Karate. Fevereiro de 2019).

$\mathrm{Na}$ fala da professora $\mathrm{E}$. as estruturas físicas colocaram em xeque a segurança dos alunos sob sua responsabilidade, o que acabou por exercer significativa pressão na mesma. Ainda que a professora tentasse criar novos modos de trabalhar, que é um importante elemento para a manutenção ou desenvolvimento da saúde mental (DEJOURS; BARROS; LANCMAN, 2016), a falta de reconhecimento e de sinceridade da instituição, para a criação de um local físico mínimo para o desenvolvimento das aulas, foi ao longo dos anos se tornando insuportável.

Em nome de um ideal de transformação social, muitos professores se vinculam aos inúmeros projetos sociais voluntários pela cidade. Buscando "dar a sua contribuição" 
para o desenvolvimento de determinado território. No entanto, a atuação aparentemente inofensiva e que poderia se ligar a noção de bem-estar psicológico, tanto dos professores-voluntários, quanto dos alunos receptores deste trabalho, podem disfarçar as violências e o abuso das instituições: "Agora a decepção que eu tive assim no Karate, é quando você vai atrás de um político, e você vai organizar um torneio, igual aconteceu comigo, fui atrás de um certo político aqui de Cotia: 'será que você poderia ajudar? Eu vou organizar um torneio para as crianças de trabalho social, eu vou precisar de umas medalhas e tal...Não são tantas medalhas ou tantos troféus assim'. Aí o político falou assim: 'poxa G. você pede demais!' Eu falei: 'político, esse evento, não é para mim, é um trabalho que vocês poderiam estar fazendo para essas crianças e não fazem'.". (Professor G. 56 anos. 40 anos como professor de Karate. Março de 2019).

As implicações da falta de organização e de engajamento da gestão pública concomitantemente com os limites que a falta de recurso financeiro impõe, podem acarretar a sobrecarga, assim como as dificuldades em se manter o equilíbrio psíquico. Esse professor, preterido pela possibilidade de reconhecimento simbólico no trabalho, perde as vias de gratificação que o trabalho possibilita: a gratificação pelo julgamento de utilidade e pelo julgamento estético.

Para Dejours (2011) é o julgamento estético que confere o reconhecimento de quem trabalha por seus pares, sendo severo e exigente, mas que oferece um sentimento de pertencimento a um coletivo que só pode ser proferido pelos colegas de ofício. Já o julgamento da utilidade é ainda mais evidente, já que é realizado não somente pelos superiores (neste caso o mestre da modalidade praticada de Karate), mas também pelos alunos, pais e sociedade de um modo geral: "Agora a prefeitura, por ser o ano antes das eleições, eles estão mais interessados, então eu fiz um pedido de equipamento, eles me disseram que a semana que vem entregam, mas é bem mais complicado. Em prefeitura eles não ligam muito, são só números. A hora que vai chegando à eleição aí é interessante, 52 alunos. Então são 52 famílias, né?". (Professor L. 39 anos. 28 anos como professor de Karate. Março de 2019).

As seduções que são feitas na campanha eleitoral, parecem usar da legitimidade do trabalho voluntário e engajado socialmente dos professores para potencializar os seus códigos, linguagens e aproximações com a comunidade. Ainda assim e, mediante 0 cenário de tamanha falta de estrutura, não é possível renunciar às poucas benesses que são típicas do período eleitoral. Resta aos professores a dose de cordialidade necessária para captar os parcos recursos e a esperança de um novo cenário com uma nova gestão.

\section{SOBRE AS VIVÊNCIAS DE SOFRIMENTO}

Segundo Dejours (2012) trabalhar é enfrentar o fracasso, já que os trabalhadores são colocados frente a frente com a necessidade de realizar uma determinada atividade, e sua possibilidade de não conseguir realizá-la, de não saber fazê-la, de não dar certo. Por esta razão, a psicodinâmica do trabalho se debruça em duas vertentes perante este sofrimento inerente ao trabalho. Na primeira, teríamos o sofrimento criador, que possibilita a engenhosidade e os novos modos de fazer. Tal sofrimento é chamado de sofrimento criativo. Já na segunda via, teríamos o sofrimento patogênico, vivenciado pelo trabalhador quando a sua relação com a organização do trabalho e/ou fatores externos impede-o de exercer seu ofício e utilizar sua criatividade (DEJOURS, 2011). 
Dejours, Barros e Lancman (2016) destacaram que os esforços para realizar uma atividade, se reconhecidos, conferem ao trabalhador a possibilidade da realização de si mesmo, gerando vivencias de prazer. Contudo, quando não há o reconhecimento (seja dos pares, da hierarquia ou dos subordinados) o sujeito fica exposto ao sofrimento patogênico.

Três importantes entraves estão postos na fala dos professores, geradores de significativo sofrimento. O primeiro deles é vinculado as questões políticas, de falta de investimento no esporte, no lazer e na educação, versando sobre a exploração dos projetos sociais em épocas de campanha eleitoral (como apresentado anteriormente). $O$ segundo entrave é com relação a relação das academias (de ginástica ou especializada em lutas) e escolas (privadas, aulas direcionadas para o público infantil) perante a gestão dos professores. Sobre este segundo foco temos os seguintes apontamentos: "Nas academias eles querem ver o resultado, e o resultado que eles querem ver é financeiro e não resultado de transformação." (Professor R. 47 anos. 12 anos como professor de Karate. Fevereiro de 2019). Já o professor H. aponta que: "Porque quando você está dando aula numa academia o cara quer saber quantos alunos você tem e como você vai "catar" mais atletas, mais alunos. (...). Daí eu não posso falar que ele (o aluno) não está preparado, se ele vai trazer retorno financeiramente para a academia. (...) em academia, para ganhar mais tem que ter mais aluno. Essa é a linguagem. "Teve esse desconto aquil" "fulano parou de vir", se você não tem condições de manter esse aluno, você não tem condições de manter esse salário, é bem isso, é bem financeiro, é a base de troca. E a qualquer momento que você seja flexível, você sai perdendo, é muito difícil. (...) Teve academias que eu cheguei e não recebia um bom dia do dono". (Professor H. 30 anos. 16 anos como professor de Karate. Fevereiro de 2019).

Tal vivência narrada pelo Professor $\mathrm{H}$. é convergente a situações de assédio moral. Para Heloani e Barreto (2018) é preciso enfatizar a violência presente nos assédios, seu tratamento judicial; suas práticas na administração, na intensificação do trabalho; seus elementos causais, seus riscos psicossociais, sua história, suas expressões em diferentes contextos. São nuances que muitas vezes passam desapercebidas aos trabalhadores, gerando culpabilização, solidão e adoecimentos diversos.

Convergente a este relato temos a fala da professora E.: "Eu dou aula em 4 escolas, três delas estão me cobrando uma porcentagem sobre o meu trabalho, que eu acho alta, de $20 \%$ a $25 \%$. Uma delas eu uso ainda a energia elétrica, porque a aula é mais a noite, então a luz eu uso, eu acabo usando por causa do horário da aula, que é das 5h30 às 6h30. E outra, eu só uso o local que ele fica à disposição o tempo todo, ele não é usado pelos alunos, é um local já para aulas de Karate, música e balé. Eu uso esse local, não uso energia, não uso luz, mas eles me cobram $20 \%$. Então uma escola está cobrando $25 \%$ e essa outra escola, cobrando $20 \%$ sobre o meu trabalho. O que aconteceu? O que eu estava ganhando o ano passado, mesmo eu aumentando o valor da mensalidade, eu vou ganhar menos que o ano passado, por causa dessa cobrança que as escolas estão fazendo em cima da mensalidade". (Professora E., 44 anos. 15 anos como professora de Karate. Fevereiro de 2019).

Nestes retratos, vê-se a extrema precariedade, as pressões para a busca e a manutenção do aluno em sala, as contradições da organização de trabalho e a ausência de regulamentação do ofício (nenhum professor tinha a carteira profissional assinada ou contrato registrado). O cenário é de total abandono de fiscalizações laborais. Tal realidade de sofrimento, de falta de rede de apoio e fiscalizações é convergente a outros 
tantos campos de atuação, como já mapeados pela Psicodinâmica do Trabalho (BUENO; MACÊDO, 2012; DEJOURS, 2017; PONTES et al., 2020).

Quando se pensa na atuação em projetos sociais o sofrimento se debruça nas limitações impostas pela falta de condições mínimas estruturais. Atuar em projeto social é muito mais do que doar sua força de trabalho, é também ter despesas diversas extras, tal como expresso na fala a seguir: "O meu trabalho era voluntario, então, alguns alunos que eu sentia que gostavam muito, que se esforçavam muito, eu pagava para eles para eles poderem fazer os exames. E tinha muita gente que doava kimono, e daí a doação de kimono eu segurava até a época de fazer exame". (Professora E., 44 anos. 15 anos como professora de Karate. Fevereiro de 2019).

Em razão disso, tem-se sempre uma fala reivindicatória, ainda que sempre acompanhada de feições tristes e com doses de desesperança: "A própria cidade em si, ela não se preocupa tanto com esporte, ela não tem uma visão tão ampla com o esporte como a gente pensa, então eu acho que as crianças têm pouco espaço. Esse projeto que a gente tem a gente sobrevive, a gente tenta manter, mas já pensou se tivesse 0 apoio de um governo? De uma prefeitura ou algo assim que pudesse estar caminhando junto com a gente?". (Professor M. 43 anos. 14 anos como professor de Karate. Fevereiro de 2019).

Há ainda um entrave da ordem do ensino em si, da didática, da disseminação do conhecimento: "Ter a responsabilidade de dar aula, no começo, foi bem difícil, até eu me acostumar a ter uma linguagem diferente. Porque uma coisa que eu identifiquei, é que realmente você começa a aprender mais quando você tem que ensinar, porque começa a vir perguntas novas, as dúvidas dos seus alunos, muitas vezes são as nossas também, só que quando é uma dúvida particular, pelo menos para mim eu não buscava saber o que era. Saber por que o soco é de uma forma, porque não pode ser de outra forma. Mas aí, quando seus alunos começam a te perguntar, você fica naquela obrigação, e de saber, poder passar a informação correta, é uma outra responsabilidade". (Professor R.H. 32 anos. 4 anos como professor de Karate. Fevereiro de 2019).

Vê-se aqui que não basta a aplicação fria das técnicas de Karate, já que se trata de um trabalho em que o contato humano é essencial, que requer sensibilidade, liderança e conhecimento. O sofrimento narrado pelo professor talvez também decorresse do fato de sua formação não ser em Educação Física, mas sim em Administração de Empresas, tendo até então pouco manejo com a prática de ensino. Além disso, o referido professor gerenciava um empreendimento familiar, fato que dificultava seu engajamento com a prática do ensino e sua performance nas competições de Karate. Vive-se, neste último caso, as limitações de seu saber técnico que não possibilitava traduzir na prática de ensino a existência do saber prático construído através da experiência.

\section{SOBRE AS VIVÊNCIAS DE PRAZER}

Habitualmente se atribui a noção de prazer a associação entre a descarga gerada após uma situação de aumento de tensão. Nessa concepção, o prazer viria como uma situação desejada, ou a ser conquistada, como um estado de plenitude. No entanto, ao se pensar tal temática associada ao trabalho é importante entender que as vivências de prazer com o ofício estão inseridas dentro de um processo contínuo de invenção de novas regras. Da possibilidade em se poder atuar ativamente no seu trabalho, colocando a inteligência prática em ação. Nesse sentido Dejours, Barros e Lancman (2016), 
apontam que quando a relação entre o trabalhador e a organização do trabalho permite o livre jogo do funcionamento psíquico do sujeito, o trabalho consegue ocupar um lugar estruturante, que propicia o equilíbrio psíquico e construção permanente da identidade.

Se nos chama a atenção as condições precárias de trabalho ou ainda as inúmeras dificuldades dos professores para a execução do seu ofício, destaca-se com semelhante vigor, nas entrevistas aqui realizadas, o prazer com o ensino do Karate, sobretudo aquele vinculado aos projetos sociais: "Desde o começo tem uma academia que eu estou, eu estou há 12 anos lá. Então eu tenho liberdade, eu já deixo bem claro para os donos da academia que o trabalho tem que ser feito do meu jeito não é, senão eu não consigo desenvolver, senão eu prefiro não trabalhar". (Professor L. 39 anos. 28 anos como professor de Karate. Março de 2019).

Nessa mesma direção o professor M. nos aponta: “(...) se eu for trabalhar de personal, se eu for trabalhar numa academia eu tenho que reservar um tempo para o meu projeto. Se eu for dar aula em algum condomínio, personal em alguma empresa, eu tenho que separar um tempinho para fazer os meus treinos de Karate, então está sempre envolvido comigo, como se fosse o número 8, um caminho sem fim, acho que é nisso que eu resumo, minha história no Karate". (Professor M. 43 anos. 14 anos como professor de Karate. Fevereiro de 2019). Ainda nessa direção o professor R. nos agrega: "(...) as meninas que eu dava aula lá na ONG, tinham sido molestadas, tinham sido estupradas, e aí eram tímidas, retraídas, e quando eu notava, lá vinha na ONG, os carros do ministério público: "O que é que você faz com elas professor. Como conseguiu essa transformação?". Daí eu falava, "Quem faz é o esporte, eu sou só o professor delas!". E é por isso que eu acredito, o esporte, a luta e na transformação". (Professor R. 47 anos. 12 anos como professor de Karate. Fevereiro de 2019).

Vê-se nessas falas que os professores não se limitam à execução estrita das prescrições, isto é, a disseminação do conhecimento, ou a manutenção dos alunos em sala. Eles estão a todo momento se reajustando a prescrição, transformando as normativas e usando toda a sua inteligência prática para que o trabalho seja executado. Temos aqui o claro comprometimento da subjetividade com o bem-fazer no trabalho, por isso concebemos que este jamais pode ser neutro diante do eu e da saúde mental (DEJOURS, 2012). Assim, o zelo no trabalho está diretamente associado ao engajamento afetivo da subjetividade em conflito com as realidades laborais, tão duramente vividas (DEJOURS, 2017).

Convergente a esta discussão Segnini(2020) localizou em sua análise o trabalho de bailarinos e atletas de rendimento, permeados em seus cotidianos pelo zelo e engajamento com a atividade. Para a autora é o corpo que labuta cotidianamente nesses contextos: o corpo biológico, técnico e erógeno; sendo este último palco da subjetividade, do sofrimento e do prazer. Para a autora, bailarinos e atletas são assim trabalhadores do corpo, que implica um longo e doloroso trabalho que, normalmente, se inicia na infância e pressupõe um engajamento pleno com a atividade.

Observa-se assim que a construção singular de trabalho dos professores, passa pela sua relação com o outro, entendido aqui com o coletivo do qual está inserido, igualmente consigo próprio, o que requer a constante e intensa mobilização psíquica.

\section{Discussão}


Diante do percurso investigativo realizado até aqui sobre as condições de trabalho e equação do sofrimento e do prazer, na atuação dos professores de Karate na cidade de Cotia, pode-se dizer que muitas são as exigências colocadas pelas academias, escolas, alunos, projetos sociais. Assim como os abusos feitos em épocas eleitorais para captar votos, se beneficiando de uma atuação longa e da dura realidade enfrentada pelos trabalhadores.

As realidades aqui apresentadas contribuem para que estes professores fiquem atentos à necessidade urgente de articulação entre si, dos modos de pensar coletivamente sua categoria profissional, unindo forças para além da disseminação técnica dos movimentos do Karate ou da filosofia em si. Daí a importância das relações sociais entre os pares, assim como também o fomento de um olhar permanentemente crítico sobre as exigências que lhe são colocadas pelos diferentes contextos de trabalho. Por meio desse olhar, é possível compreender que a subjetividade está fundamentalmente presente no cotidiano do professor, tendo em vista a natureza de sua função, diretamente vinculada à formação educacional dos(as) alunos(as).

Podemos considerar que a falta de condições mínimas e estáveis de trabalho, acarretam, por vezes, maiores expressões de sofrimento, se sobrepondo ao prazer com o ofício. Ainda assim, no final das contas, algo escapa da lógica dura do sofrimento, já que os professores, em sua maioria, compreendem um papel social vigoroso e tentam costurar novos modos de contornar as mazelas encontradas. Esse enfrentamento fica visível quando consideramos que a maioria dos entrevistados possuíam mais de dez anos de experiência na função, tendo vivido toda uma série de problemas e assédios, mas que, no final das contas insistiram nesta carreira.

O distanciamento da psicologia do trabalho no contexto do esporte reforça o não reconhecimento de que esta é uma atividade produtora de valor econômico, que ultrapassa os regimes formais de emprego ou às organizações, com suas demandas por performance, que pode propiciar prazer e sofrimentos de diversas ordens. Ao se apropriar deste debate, em uma engajada postura ético-política, visamos explicitamente contribuir para a transformação destes contextos laborais, propiciando o questionamento das tensões inerentes à relação capital-trabalho, posta no mercado que envolve o esporte.

Por fim, destacamos aqui a importância de considerar o quanto o processo de disseminação do conhecimento envolve uma dimensão política, aliada a dimensão pedagógica, tanto no aspecto individual, quanto coletivo. Por esta razão, este artigo também convida a Psicologia do Trabalho a unir forças à Psicologia Social do Esporte, visando a compreensão e o enfrentamento coletivo, das realidades laborais que envolvem o contexto esportivo e da atividade física, colocando tais pautas na necessária e urgente ampliação e diversificação da agenda de pesquisas.

\section{CONSIDERAÇÕES FINAIS}

Com o auxílio dos pressupostos epistemológicos e metodológicos da psicodinâmica do trabalho foi possível compreender as principais questões que se vincularam as condições de trabalho, as vivências de prazer e de sofrimento com o trabalho em professores de lutas em uma cidade metropolitana do estado de São Paulo.

Nessa pesquisa foi possível notar que o trabalho dos professores estava rodeado por dificuldades básicas quanto a uma estrutura física mínima, que pudesse garantir a 
integridade dos mesmos e de seus alunos. As condições de trabalho enfrentadas pelos professores foram descritas como precárias, tanto em termos dos espaços físicos, como dos demais elementos mínimos (como água para beber). Como paliativo, esses trabalhadores utilizam sua inteligência astuciosa, buscando modos de lidar com a falta de recursos, os problemas da gestão, da falta de investimentos nos projetos sociais e dos assédios vividos nos bairros mais abastados.

Notou-se uma intensa mobilização psíquica dos professores, sobretudo quando eles se identificam pelas necessidades dos alunos que advém de situações sociais críticas. Esse funcionamento gerou desgaste e adoecimento, sendo estes aspectos quase sempre negados por eles.

Esta investigação científica também evidencia lacunas, abre espaços para novas pesquisas e reflexões acadêmicas, considerando o mesmo campo - trabalho no contexto do esporte, seja ele voltado para o lazer, bem-estar, formação educacional ou no alto-rendimento - fundamentadas em perspectivas críticas do trabalho. Salienta-se aqui a necessidade de se pensar as questões de gênero e de raça, bem como futuros aprofundamentos que versem no assédio moral que pode ocorrer em diferentes situações.

\section{REFERÊNCIAS}

ANTUNES, R. Os modos de ser da informalidade: rumo a uma nova era da precarização estrutural do trabalho? Serv. Soc. Soc., v. jul./set., n. 107, p. 405-419, 2011.

ANTUNES, R. L. C. Adeus ao trabalho? Ensaio sobre as metamorfoses e a centralidade do mundo do trabalho. $3^{\mathrm{a}}$ ed. Campinas: Cortez, 2008.

AWI, F. Filho teu não foge à luta. Rio de Janeiro: Intrínseca, 2012.

BARREIRA, C. R. A. Combate, uma arqueologia fenomenológica: da arte marcial ao MMA sob uma nova perspectiva em psicologia do esporte. 2014. Universidade de São Paulo de Ribeirão Preto, 2014.

BUENO, M.; MACÊDO, K. B. A Clínica psicodinâmica do trabalho: de Dejours às pesquisas brasileiras. Ecos, v. 2, n. 2, p. 306-318, 2012.

CAMILO, J. A. de O. A naturalização do mal e os assédios no esporte de rendimento. In: Trabalho e Esporte: invisibilidade e desafios. São Paulo: Laços, 2020. p. 247-255.

CAMILO, J. A. de O.; RABELO, I. S. Precariedade e invisibilidade do trabalho dos atletas de alto-rendimento. In: Psicologia Social do Esporte. São Paulo: Képos, 2019. p. 73-88.

CAMILO, J. A. de O.; SPINK, M. J. P. Las Artes Marciales Mixtas (MMA): deporte, espectáculo y economía. Revista de Artes Marciales Asiaticas, v. 13, n. 1, p. 20-34, 2018.

DEJOURS, C. Subjetividade, trabalho e ação. Revista Produção, v. 14, n. 3, p. 27-34, 2004.

DEJOURS, C. A metodologia em psicodinâmica do trabalho. In: EDITORA FIOCRUZ, E. P. (Ed.). CHRISTOPHE DEJOURS: Da psicopatologia à psicodinâmica do trabalho. [s.l: s.n.]p. 125-150.

DEJOURS, C. Trabalho Vivo. Brasília: Paralelo 15, 2012.

DEJOURS, C. Psicodinâmica do trabalho: casos clínicos. Porto Alegre - São Paulo: Editora Dublinense, 2017.

DEJOURS, C.; BARROS, J. de O.; LANCMAN, S. A centralidade do trabalho para a construção da saúde. Revista de Terapia Ocupacional da Universidade de São Paulo, v. 27, n. 2, p. 228, 2016. Disponível em: <http://www.revistas.usp.br/rto/article/view/119227>.

DEJOURS, C.; NETO, T. G. a. R. M. Psicodinâmica do trabalho e teoria da sedução. Psicologia em Estudos, v. 17, n. 3, p. 363-371, 2012. Disponível em: <http://dx.doi.org/10.1590/S141373722012000300002>. 
DRENATEC ENGENHARIA S/C; INSTITUTO DE PESQUISAS TECNOLÓGICAS. RELATÓRIO TÉCNICO No 88 219-205. Plano de Desenvolvimento e Proteção Ambiental da Bacia do Rio Cotia: Caracterização Regional. 2007.

DRUCK, G. A terceirização sem limites: mais precarização e riscos de morte aos trabalhadores. Cad. Saúde Pública, v. 32, n. 6, 2016.

FERREIRA JUNIOR, N.; RABELO, I. S.; CAMILO, J. A. de O. Carreira, transição e outros dilemas da "profissão" atleta. In: Do pós ao neo olimpismo: Esporte e Movimento olímpico no século XXI. São Paulo: Laços, 2019. p. 119-144.

HELOANI, R.; BARRETO, M. Assédio moral no trabalho: gestão por humilhação. Paraná: Juruá, 2018.

MERLO, Á. R. C.; MENDES, A. M. B. Perspectivas do uso da psicodinâmica do trabalho no Brasil: teoria, pesquisa e ação. Cadernos de Psicologia Social do Trabalho, v. 12, n. 2, p. 141-156, 2009.

MOLINIER, P. O Trabalho e a Psique: uma introdução a psicodinâmica do trabalho. São Paulo: Paralelo 15, 2016.

OLIVEIRA, M. A. de et al. De "mãos vazias" a "mãos com luvas": Uma análise sociológica sobre Karate e os Jogos Olímpicos. Olimpianos - Journal of Olympic Studies, v. 2, n. 1, p. 324-342, 2018.

OLIVEIRA, M. A. de; TELLES, T. C. B.; BARREIRA, C. R. A. De Okinawa aos Jogos Olímpicos: o Karate. In: Do pós ao neo olimpismo: Esporte e Movimento olímpico no século XXI. São Paulo: Laços, 2019. p. 327-348.

ORGANIZAÇÃO DAS NAÇÕES UNIDAS NO BRASIL. Esporte para o desenvolvimento e a paz:

informativo da ONU no Brasil, 2016. Disponível em:

http://unesdoc.unesco.org/images/0024/002443/244329POR.pdf.

PONTES, K. de A. do E. S. et al. O olhar da equipe de enfermagem sobre o trabalho em uma unidade neonatal: uma intervenção com foco na atividade. Revista Brasileira de Saúde Ocupacional, v. 45, p. $1-$ 9, 2020.

SEGNINI, M. P. Quando tudo o que se tem é o corpo: contribuições da clínica do trabalho sobre a lesão física em bailarinos e atletas de alto rendimento. In: Trabalho e Esporte: invisibilidade e desafios. São Paulo: Laços, 2020. p. 117-128.

SPENCER, D. C. Sensing violence: An ethnography of mixed martial arts. Ethnography, v. 15, n. 2, p. 232 254, 2014.

WACQUANT, L. Punir os pobres: a nova gestão da miséria nos Estados Unidos. Rio de Janeiro: Editora Revan, 2003. 